\title{
Costs of managing adverse events in the treatment of first-line metastatic renal cell carcinoma: bevacizumab in combination with interferon- $\alpha 2$ a compared with sunitinib
}

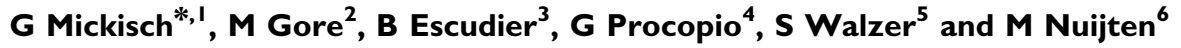 \\ 'Center of Operative Urology, Bremen 28277, Germany; ${ }^{2}$ The Royal Marsden Hospital, London SW3 6J), UK; ${ }^{3}$ Institut Gustave Roussy, Villejuif 94805 , \\ France; ${ }^{4}$ Fondazione 'IRCCS 'Istituto Nazionale dei Tumouri', Medical Oncology, Milan 20133, Italy; ${ }^{5} \mathrm{~F}$. Hoffmann-La Roche Ltd, Basel CH-4070, \\ Switzerland; ${ }^{6}$ Erasmus University, Rotterdam 1546 LG, The Netherlands
}

\begin{abstract}
BACKGROUND: Bevacizumab plus interferon- $\alpha 2$ a (IFN) prolongs progression-free survival to $>10$ months, which is comparable with sunitinib as first-line treatment of metastatic renal cell carcinoma (RCC). The two regimens have different tolerability profiles; therefore, costs for managing adverse events may be an important factor in selecting therapy.

METHODS: Costs of managing adverse events affecting patients with metastatic RCC eligible for treatment with bevacizumab plus IFN or sunitinib were evaluated using a linear decision analytical model. Management costs were calculated from the published incidence of adverse events and health-care costs for treating adverse events in the United Kingdom, Germany, France and Italy.

RESULTS: Adverse event management costs were higher for sunitinib than for bevacizumab plus IFN. The average cost per patient for the management of grade 3-4 adverse events was markedly lower with bevacizumab plus IFN compared with sunitinib in the United Kingdom (€ 475 vs $€ 804)$, Germany (€I785 vs €|367), France (€2590 vs €|6|8) and Italy (€89| vs €402). The main cost drivers were lymphopaenia, neutropaenia, thrombocytopaenia, leucopaenia and fatigue/asthaenia for sunitinib; and proteinuria, fatigue/ asthaenia, bleeding, anaemia and gastrointestinal perforation for bevacizumab plus IFN.

CONCLUSION: The costs of managing adverse events are lower for bevacizumab plus IFN than for sunitinib. The potential for cost savings should be considered when selecting treatments for RCC.

British Journal of Cancer (2010) 1 02, 80-86. doi:I0.1038/sj.bjc.66054I7 www.bjcancer.com
\end{abstract}

Published online 17 November 2009

(c) 2010 Cancer Research UK

Keywords: adverse events; bevacizumab; cost; management; sunitinib

Renal cell carcinoma (RCC) is the most common cancer of the kidney, with an incidence of 40000 (3.1\% of all cancer cases) annually and accounting for 26000 deaths $(2.3 \%$ of all cancer deaths) in Europe (Ferlay et al, 2007). The treatment landscape for metastatic RCC is changing, as a greater understanding of the biological processes involved in RCC development and growth, in particular the function of tumour angiogenesis, supports the development of more specific and effective therapies.

Bevacizumab (Avastin) is a humanised monoclonal antibody that precisely inhibits vascular endothelial growth factor (VEGF), the key mediator of tumour angiogenesis. In combination with cytotoxic chemotherapy, bevacizumab has demonstrated significant clinical benefits in several tumour types including metastatic colorectal (Hurwitz et al, 2004; Saltz et al, 2008), breast (Miller et al, 2007; Miles et al, 2008) and non-small-cell lung cancer (Sandler et al, 2006; Manegold et al, 2007). In metastatic RCC, initial phase II trials demonstrated that bevacizumab monotherapy

*Correspondence: Professor G Mickisch, Center of Operative Urology Bremen, c/o Academic Hospital Bremen, Robert Koch Strasse 34a, Bremen 28277, Germany; E-mail: gerald.mickisch@coub.de

Received 27 April 2009; revised 22 September 2009; accepted 12 October 2009; published online 17 November 2009 is active and well tolerated in previously treated and treatmentnaive patients (Yang et al, 2003; Bukowski et al, 2007). A large international, double-blind, randomised, controlled phase III trial (AVOREN) demonstrated that first-line bevacizumab combined with interferon- $\alpha 2 \mathrm{a}$ (IFN, Roferon) significantly improved median progression-free survival (PFS: 10.2 vs 5.4 months; hazard ratio $(\mathrm{HR})=0.63, P=0.0001)$ and objective response rate (ORR: $31 \mathrm{vs}$ $13 \%, P=0.0001$ ) compared with IFN plus placebo (Escudier et al, 2007). On the basis of these positive data, bevacizumab combined with IFN is approved in Europe for the first-line treatment of patients with advanced and/or metastatic RCC. A second phase III study, conducted in the United States (CALGB 90206), confirmed the significant benefit of bevacizumab and IFN vs IFN, with improvements in median PFS (8.5 vs 5.2 months; $\mathrm{HR}=0.71$, $P<0.001)$ and ORR (26 vs 13\%, $P<0.001)$ (Rini et al, 2008).

A number of other novel biological agents are available for the treatment of metastatic RCC, including sunitinib malate (Sutent), an orally active inhibitor of multiple receptor tyrosine kinases including VEGF receptors $1-3$ and platelet-derived growth factor receptor- $\alpha$ and $-\beta$ (Mendel et al, 2003). Sunitinib is also approved for first-line treatment of metastatic RCC on the basis of an open-label phase III trial showing significant improvement in ORR (47 vs $12 \%, P<0.0001)$ and median PFS (11.0 vs 5.0 months; $\mathrm{HR}=0.539, P<0.001$ ) when compared with IFN (Motzer et al, 2007). 


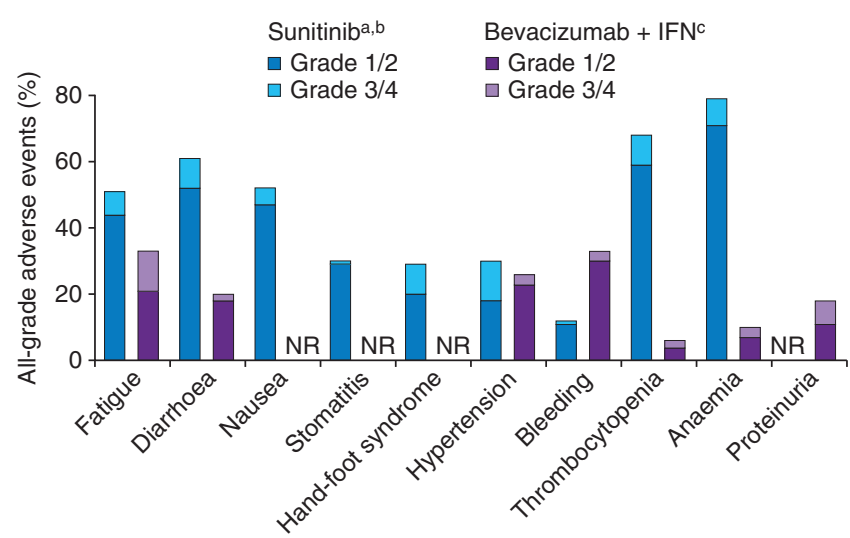

Figure I Frequency and severity of principal adverse events in patients with metastatic RCC treated with bevacizumab plus IFN or with sunitinib (Escudier et al, 2007; Motzer et al, 2007; Negrier et al, 2008). IFN = interferon- $\alpha 2 \mathrm{a}$; $\mathrm{NR}=$ not reported; $\mathrm{RCC}=$ renal call carcinoma.

The results of these recent phase III trials in RCC suggest that the efficacy of bevacizumab plus IFN is comparable with that of sunitinib in the first-line treatment setting (Escudier et al, 2007; Motzer et al, 2007; Coppin et al, 2008). However, clinical data suggest that the two regimens have different tolerability profiles with respect to the type, severity and frequency of adverse events experienced by patients (Figure 1). These differences in the tolerability profiles of bevacizumab and sunitinib most likely reflect their different mechanisms of action.

The most frequently reported grade $3-4$ adverse events in phase III trials of bevacizumab plus IFN include fatigue and asthaenia, hypertension, anorexia, bleeding, pyrexia and proteinuria; the majority of these are mild to moderate and manageable, and only a low incidence of grade 3-4 events is observed (Escudier et al, 2007; Rini et al, 2008). A retrospective subgroup analysis of the AVOREN trial has shown that the tolerability of the regimen is improved when lower doses of IFN are used in combination with bevacizumab (Melichar et al, 2008): IFN dose reduction led to a substantial decrease in the incidence of grade 3-4 adverse events 6 weeks after dose reduction compared with 6 weeks before dose reduction (18 vs 44\%), while efficacy was maintained.

The most frequently reported grade $3-4$ adverse events reported with sunitinib as first-line treatment of metastatic RCC include diarrhoea, vomiting, hypertension, hand-foot syndrome, leucopaenia, neutropaenia, thrombocytopaenia and mucositosis (Motzer et al, 2007; Negrier et al, 2008). The majority of adverse events associated with sunitinib are managed by sunitinib dose reduction or withdrawal (Sutent SmPC).

The development of severe adverse events is likely to require additional treatment and/or hospitalisation. Adverse event management costs, particularly hospitalisation, create an additional demand on health-care resources. Thus, when making a treatment choice for first-line RCC, the costs of managing adverse events are an important consideration from the perspective of health-care providers and physicians. Currently, there are few published data relating to management costs of adverse events in patients with metastatic RCC. This paper presents the results of a cost analysis to assess the estimated costs of managing adverse events associated with bevacizumab plus IFN compared with those associated with sunitinib for first-line treatment of RCC in the United Kingdom, Germany, France and Italy.

\section{MATERIALS AND METHODS}

An Excel-based linear decision analytical model was developed to calculate and compare the costs of management of all grades of adverse events according to standard clinical practice for bevacizumab plus IFN and sunitinib used as first-line treatment of metastatic RCC. The model was populated using the total incidence of grade 1-4 adverse events reported in phase III trials in this disease setting (Escudier et al, 2007; Motzer et al, 2007), and with cost data associated with the management of adverse events from the perspective of health-care providers in the United Kingdom, Germany, France and Italy.

Cost data for the United Kingdom were obtained from a review of the published literature in the MEDLINE database using the adverse event description 'type of adverse event' and 'cost' and 'UK' and 'RCC'. If this search strategy was unsuccessful, alternative search strategies were 'type of adverse event' and 'cost' and 'UK' and 'oncology' or 'type of adverse event' and 'cost' and 'UK'. The same search terms were also used to obtain cost information from the UK National Institute for Health and Clinical Excellence (NICE). The primary perspective of this analysis was the same as that of the UK National Health Service.

Cost data for Germany were calculated from the diagnosisrelated group (DRG) funding system catalogue (2008) and the from Einheitlicher Bewertungsma $\beta$ stab (EBM) catalogue 2008 (Diagnosis Related Groups in Germany 2008; G-DRG system 2008; Einheitlicher Bewertungsma $\beta$ stab für ärztliche Leistungen, Kassenärztliche Bundesvereinigung Berlin, 2008). Cost calculations in the DRG system are all inclusive, reflecting the costs of medicines, staff and maintenance, and provide an indication of the total cost for treating adverse events assuming that there is no severe underlying disease or complication. The EBM catalogue assigns points and costs per point for physician activities associated with costs of ambulatory treatment, but does not include medication costs. In this study, EBM points were assigned a value of $€ 0.05$; thus, 900 physician points corresponded to a cost of $€ 4.50$. To take into account the 2009 changes in the German EBM system, a point value of 3.5 cents was also applied.

In France, the cost of drugs was obtained from the Banque Claude Bernard database (Banque Claude Bernard, Group Cegedim, Boulogne Billancourt, France, 2007) and from the Pharmacie centrale des Hopitaux de Paris (APHP) (Pharmacie centrale des Hôpitaux de Paris, France, January, 2007). Costs for laboratory tests and examinations were derived from official tariff lists (Classification Commune des Actes Médicaux, CCAM V10, 2007; Table Nationale de codage de Biologie - Version 26 December, 2007). Hospitalisation costs (mean cost per stay) were estimated using the French DRG hospital database and the Etude Nationale de Couts (ENC) 2006 (Base de données PMSI, 2006; Etude Nationale de Coûts, 2006).

The assessment for Italy used information on the cost of treating adverse events from the report of a Delphi panel of experts from five clinical practices (Capri et al, 2007), from the Italian national DRG tariff (Conferenza delle Regioni e Province Autonome) and data from studies by Nuijten et al (2002) and Jansen et al (1997).

The base-case analysis conducted using the decision analytical model included all grades of adverse events, using as a threshold the cumulative total of events responsible for $\geqslant 80 \%$ of total management costs. An additional scenario analysis was also conducted based only on the costs of managing grade 3-4 adverse events. As modelling studies are associated with uncertainty associated with input parameters, the robustness of the model was tested using sensitivity analyses based on varying hospitalisation costs within plus or minus $10 \%$ and by excluding the two most costly adverse events for bevacizumab plus IFN and with sunitinib. In Germany, medication costs are not included in the EBM cost estimates. Therefore, in Germany only, additional sensitivity analyses were conducted: first, $5 \%$ was added to the ambulatory medication costs to capture the costs of medications used to manage adverse events, and second, the effect of assigning a cost of $€ 0.03$ or $€ 0.06$ per EBM physician point was investigated. 


\section{RESULTS}

\section{United Kingdom, Germany and France}

The average cost per patient of managing all-grade and grade 3-4 adverse events varied across the countries assessed (Table 1, Figure 2). The linear decision analytical model demonstrated that for all-grade and for grade 3-4 adverse events, management costs per patient were higher for sunitinib than for bevacizumab plus IFN in the United Kingdom, Germany and France (Mickisch et al, 2008). All-grade adverse event management costs per patient in the United Kingdom, Germany and France, respectively, were $€ 1309$, $€ 1477$ and $€ 1957$ for bevacizumab plus IFN and $€ 2350, € 2071$ and $€ 5127$ for sunitinib. These differences represent potential cost savings of $€ 1041$ (44\%), $€ 594$ (29\%) and $€ 3170$ (62\%) per patient in the United Kingdom, Germany and France, respectively, for patients with metastatic RCC treated with bevacizumab plus IFN compared with sunitinib.

A similar trend of higher management costs per patient with sunitinib compared with bevacizumab plus IFN was observed for grade 3-4 adverse events (Figure 2). In the United Kingdom, Germany and France, respectively, the management costs per patient for grade $3-4$ adverse events were $€ 804$, $€ 1367$ and $€ 1618$ for bevacizumab plus IFN and $€ 1475, € 1785$ and $€ 2590$ for sunitinib. These differences represent the opportunity for cost savings of $€ 671$ (45\%), $€ 418(23 \%)$ and $€ 972$ (38\%) per patient in the United Kingdom, Germany and France, respectively, for patients with metastatic RCC treated with bevacizumab plus IFN compared with sunitinib.

The main drivers of adverse event management costs for sunitinib and bevacizumab plus IFN were generally consistent across the countries examined (Figure 3). Neutropaenia, lymphopaenia, thrombocytopaenia, fatigue/asthaenia and anaemia were the main drivers of management costs associated with sunitinib. In contrast, proteinuria and fatigue/asthaenia were the main drivers of management costs associated with bevacizumab plus IFN, although bleeding, gastrointestinal (GI) perforation, anaemia and neutropaenia were shown to be associated with high costs in individual countries.

Sensitivity analyses based on a $10 \%$ difference in hospitalisation costs and excluding the costs of treating the principal adverse events associated with treatment were consistent with the overall analyses and demonstrated that bevacizumab plus IFN remained the least expensive treatment with respect to costs for managing adverse events compared with sunitinib (Table 2). Additional sensitivity analyses conducted in Germany showed that, even after taking into account medication costs, physician costs and a point value of 3.5 cents, bevacizumab plus IFN remained the least expensive treatment with respect to costs for managing adverse events compared with sunitinib. These sensitivity analysis findings demonstrate that the analytical model was robust.

\section{Italy}

The results of the original analysis for the United Kingdom, Germany and France indicated that the vast majority of management costs for adverse events was associated with the development of grade 3-4 events. On this basis, only grade 3-4 adverse events were assessed for management costs in Italy (Procopio et al, 2008).

The average cost per patient of managing grade 3-4 adverse events for sunitinib (€891) was higher than that for bevacizumab plus IFN (€402); this difference represents an average cost saving of $€ 489$ (55\%) per patient (Figure 2). Consistent with the results in the United Kingdom, Germany and France, sunitinib and bevacizumab plus IFN had different main drivers of adverse event management costs. Lymphopaenia, hypertension, thrombocytopaenia, diarrhoea and leucopaenia were the main drivers for sunitinib treatment. In contrast, venous thrombosis, fatigue/asthaenia, GI perforation and hypertension were the main drivers of adverse event management costs for bevacizumab.

Sensitivity analyses were consistent with the main results and confirmed the cost savings of bevacizumab plus IFN in Italy. A $10 \%$ difference in hospitalisation costs and excluding the costs of treating the principal adverse events associated with sunitinib and bevacizumab plus IFN showed cost savings that were consistent with those of other countries (Table 2).

\section{DISCUSSION}

The treatment of metastatic RCC has been transformed by the recent introduction of molecularly targeted agents. Sunitinib and bevacizumab, in combination with IFN, are approved for first-line treatment of patients with metastatic RCC and recent clinical studies demonstrate that they provide comparable levels of efficacy (Escudier et al, 2007, 2009; Motzer et al, 2007; Coppin et al, 2008). In an era in which there is a choice of effective therapy, a wide range of factors should be considered when selecting treatment, including overall tolerability profiles, ease of managing adverse events and costs associated with adverse event management.

Sunitinib and bevacizumab plus IFN have tolerability profiles that show important differences and are defined to varying degrees. Common adverse events associated with bevacizumab include hypertension, proteinuria and bleeding, whereas neutropaenia, leucopaenia, anaemia and hypertension are commonly associated with sunitinib. These differences and the relative definition of the drugs' tolerability profiles are presumably related to the mechanism of action of each of the agents. The common adverse events associated with bevacizumab seem to be related directly to its precise inhibition of VEGF signalling, with a defined mechanism of action described for most. In contrast, sunitinib is a multitargeted kinase inhibitor that has been shown to have activity against a range of cell signalling pathways, as well as against VEGF, and is therefore associated with both VEGF-specific and nonVEGF-specific toxicity. However, the pathophysiology of many sunitinib-associated adverse events, including rash, stomatitis, cardiac effects and 'chemotherapy-like' events such as neutropaenia, anaemia and hand-foot syndrome, remains to be fully elucidated.

This study used safety data from the two pivotal studies of bevacizumab plus IFN and sunitinib, which also provided independently confirmed PFS data showing that the two regimens have comparable efficacy (Escudier et al, 2007, 2009; Motzer et al, 2007). In contrast, two recent indirect comparison meta-analyses suggested that suntinib provides a superior PFS benefit (Mills et al, 2009; Thompson Coon et al, 2009). Unlike these meta-analyses, this study excluded data from CALGB 90206 because this trial was open label, did not report independently confirmed data, used North American centres that have limited experience of IFN and patients seemed to have a comparatively poorer prognosis.

In this study, the costs of managing adverse events associated with these therapies in the United Kingdom, Germany, France and Italy were considerably higher for sunitinib than for bevacizumab plus IFN. Modification of basic clinical and economic assumptions (hospitalisation costs and the main cost-driving adverse events) showed that the model remained stable over the entire range of plausible values for a given parameter, and was therefore robust. The main cost drivers for sunitinib were lymphopaenia, neutropaenia, thrombocytopaenia, leucopaenia and fatigue/asthaenia. In contrast, the main cost drivers for the management of adverse events associated with bevacizumab plus IFN were fatigue/ asthaenia, proteinuria, bleeding, anaemia and GI perforation. The majority of the increased cost associated with sunitinib was related to the management of haematological toxicities, which accounted for little or none of the cost of managing 


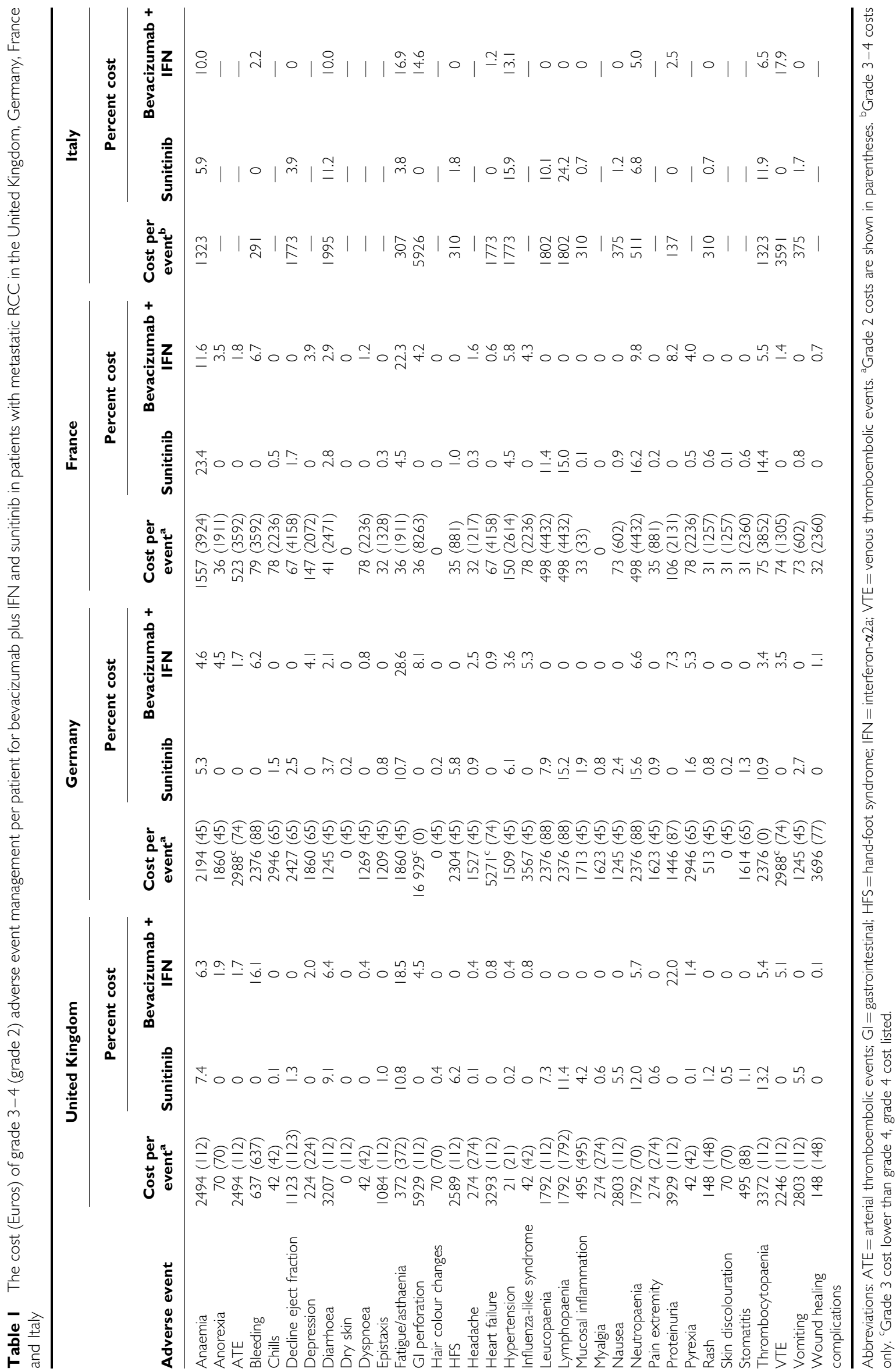




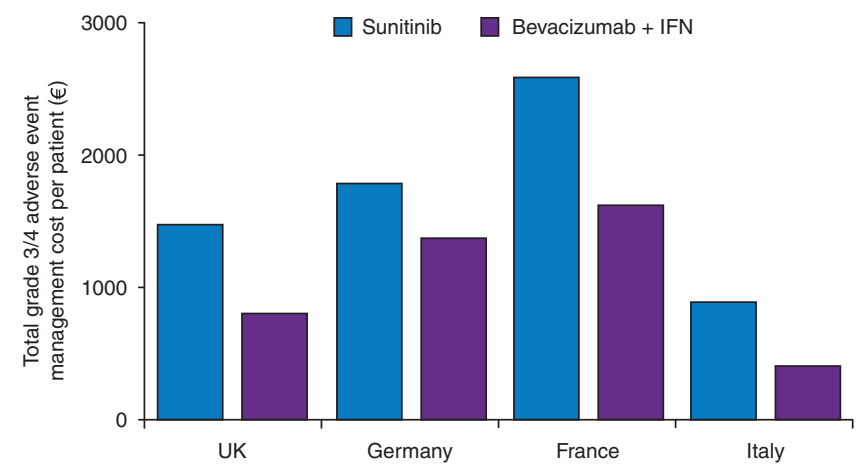

Figure 2 Total average cost per patient of managing grade 3-4 adverse events associated with bevacizumab plus IFN or with sunitinib in patients with metastatic RCC. IFN = interferon- $\alpha 2$ a; $R C C=$ renal call carcinoma aMotzer et al, 2007; ' Negrier et al, 2008; 'Escudier et al, 2007.

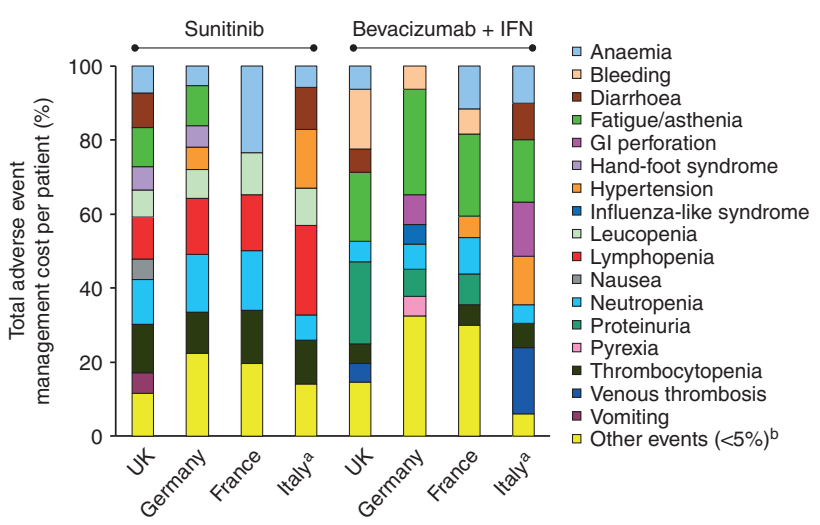

Figure 3 Cost distribution for management of adverse events with sunitinib and bevacizumab plus IFN in the United Kindgdom, Germany, France and Italy. ${ }^{a}$ On the basis of costs of managing grade 3-4 costs only; badverse events with proportional cost $<5 \%$ are grouped. IFN = interferon- $\alpha 2 \mathrm{a} ; \mathrm{Gl}=$ gastrointestinal.

adverse events associated with bevacizumab plus IFN; chemotherapy-related haematological adverse events are associated with an economic burden due to costly hospitalisation/ treatment costs and negatively affect patient quality of life (Elliott, 1996; Liou et al, 2007). This study also suggests that sunitinib involves higher costs for the management of adverse events that patients perceive as troublesome and affect their everyday activities and well-being. For example, hand-foot syndrome with sunitinib often manifests 3-4 weeks after treatment initiation (Hutson et al, 2008); it occurs predominantly on pressure points on the hands and feet, making walking and manual and sporting activities difficult. In addition, GI disorders (e.g., diarrhoea and mucosal inflammation) are common with sunitinib and can often be uncomfortable and embarrassing for the patient, interrupting daily activities (e.g., work), as well as interfering with nutrition in patients who may already be compromised in this regard.

The management strategies available for dealing with adverse events due to sunitinib and bevacizumab plus IFN may also be relevant when choosing first-line treatment for RCC. Reducing the dose of IFN used in combination with bevacizumab substantially improves the tolerability and management of IFN-related adverse events, enabling patients to remain on therapy while maintaining efficacy (Melichar et al, 2008). These promising data derived from a retrospective analysis of AVOREN need to be confirmed, most likely from the ongoing prospective phase II
Table 2 Sensitivity analyses for the linear decision analytical model in the United Kingdom, Germany, France and Italy

\begin{tabular}{|c|c|c|c|}
\hline & $\begin{array}{l}\text { Sunitinib } \\
\text { costs }\end{array}$ & $\begin{array}{c}\text { Bevacizumab } \\
+ \text { IFN } \\
\text { costs }\end{array}$ & $\begin{array}{l}\text { Cost } \\
\text { savings } \\
(\%)\end{array}$ \\
\hline \multicolumn{4}{|l|}{ United Kingdom } \\
\hline \multicolumn{4}{|l|}{ Hospitalisation cost } \\
\hline Reduction $10 \%$ & $€ 2202$ & $€ 1230$ & $€ 972(44)$ \\
\hline Increase $10 \%$ & $€ 2497$ & $€|39|$ & $€ 1106(44)$ \\
\hline \multicolumn{4}{|l|}{ Exclude main sunitinib adverse event } \\
\hline Lymphopaenia & $€ 2081$ & $€ 1309$ & $€ 772$ (37) \\
\hline Thrombocytopaenia & $€ 2040$ & $€ 1239$ & $€ 80 ।$ (39) \\
\hline Both adverse events & $€|77|$ & $€ 1239$ & $€ 532(30)$ \\
\hline \multicolumn{4}{|c|}{ Exclude main bevacizumab + IFN adverse event } \\
\hline Proteinuria & $€ 2305$ & $€ 1023$ & $€ 1282(56)$ \\
\hline Fatigue and asthaenia & $€ 2097$ & $€ 1067$ & $€ 1030(49)$ \\
\hline Both adverse events & $€ 2097$ & $€ 780$ & $€ 1317(63)$ \\
\hline \multicolumn{4}{|l|}{ Germany } \\
\hline $5 \%$ increase ambulatory treatment & $€ 2085$ & $€ \mid 482$ & $€ 603$ (29) \\
\hline \multicolumn{4}{|l|}{ Value of points } \\
\hline Three points & $€ 2030$ & $€|46|$ & $€ 569(28)$ \\
\hline Six points & $€ 2275$ & $€ । 555$ & $€ 720(32)$ \\
\hline \multicolumn{4}{|l|}{ Hospitalisation cost } \\
\hline Reduction $10 \%$ & $€ 1893$ & $€ 1340$ & $€ 553$ (29) \\
\hline Increase $10 \%$ & $€ 2250$ & $€ 1613$ & $€ 637$ (28) \\
\hline \multicolumn{4}{|l|}{ Exclude main sunitinib adverse event } \\
\hline Neutropaenia & $€ 1749$ & $€ 1380$ & $€ 369(2 \mathrm{I})$ \\
\hline Lymphopaenia & $€ 1756$ & $€ 1477$ & $€ 2279$ (16) \\
\hline Both adverse events & $€ 1434$ & $€ 1380$ & $€ 54(4)$ \\
\hline \multicolumn{4}{|c|}{ Exclude main bevacizumab + IFN adverse event } \\
\hline Fatigue and asthaenia & $€ 1848$ & $€ 1054$ & $€ 794$ (43) \\
\hline Gl perforation & $€ 207 \mid$ & $€ \mid 358$ & $€ 7 / 3(34)$ \\
\hline Both adverse events & $€ 1848$ & $€ 935$ & $€ 913(49)$ \\
\hline \multicolumn{4}{|l|}{ France } \\
\hline \multicolumn{4}{|l|}{ Hospitalisation cost } \\
\hline Reduction 10\% & $€ 4867$ & $€ 1795$ & $€ 3073(63)$ \\
\hline Increase 10\% & $€ 5386$ & $€ 2118$ & $€ 3267(61)$ \\
\hline \multicolumn{4}{|l|}{ Exclude main sunitinib adverse event } \\
\hline Anaemia & $€ 3926$ & $€ 1730$ & $€ 2196(56)$ \\
\hline Neutropaenia & $€ 4296$ & $€ 1764$ & $€ 2531$ (59) \\
\hline Both adverse events & $€ 3096$ & $€ 1538$ & $€ \mid 558(50)$ \\
\hline \multicolumn{4}{|c|}{ Exclude main bevacizumab + IFN adverse event } \\
\hline Fatigue/asthaenia & $€ 4896$ & $€|52|$ & $€ 3375(69)$ \\
\hline Anaemia & $€ 3926$ & $€ 1730$ & $€ 2196(56)$ \\
\hline Both adverse events & $€ 3696$ & $€ 1294$ & $€ 2402(65)$ \\
\hline \multicolumn{4}{|l|}{ Italy } \\
\hline \multicolumn{4}{|l|}{ Hospitalisation cost } \\
\hline Reduction 10\% & $€ 802$ & $€ 362$ & $€ 44 \mid(55)$ \\
\hline Increase 10\% & $€ 981$ & $€ 442$ & $€ 538(55)$ \\
\hline \multicolumn{4}{|l|}{ Exclude main sunitinib adverse event } \\
\hline Lymphopaenia & $€ 675$ & $€ 402$ & $€ 273(40)$ \\
\hline Hypertension & $€ 750$ & $€ 349$ & $€ 40 ।(54)$ \\
\hline Both adverse events & $€ 533$ & $€ 349$ & $€ । 84(35)$ \\
\hline \multicolumn{4}{|c|}{ Exclude main bevacizumab + IFN adverse event } \\
\hline Venous thrombosis & $€ 891$ & $€ 330$ & $€ 561(63)$ \\
\hline Fatigue/asthaenia & $€ 858$ & $€ 334$ & $€ 524(61)$ \\
\hline Both adverse events & $€ 858$ & $€ 263$ & $€ 595(69)$ \\
\hline
\end{tabular}

Abbreviations: $\mathrm{Gl}=$ gastrointestinal; IFN $=$ interferon- $\alpha 2 a .{ }^{a} \mathrm{On}$ the basis of costs of managing grade $3-4$ costs only. 
trial of bevacizumab plus 3 MIU IFN (BEVLiN). The ability to improve tolerability by using lower doses of IFN in combination with bevacizumab provides even greater cost savings compared with sunitinib in the first-line treatment of metastatic RCC (Mickisch et al, 2009). Sunitinib-related adverse events are frequently managed by a dose reduction from $50 \mathrm{mg}$ oral daily to 37.5 or $25 \mathrm{mg}$ (Sutent SmPC), suggesting that lower doses of sunitinib are better tolerated than the recommended dose, which would presumably also reduce adverse event management costs. However, recent evidence shows that PFS and ORR with sunitinib correlate with drug exposure (Mendel et al, 2003; Houk et al, 2007), suggesting that dose reduction below a certain threshold may reduce efficacy and thereby potentially affect patient outcomes.

This study considered the cost of adverse event management for bevacizumab plus IFN and sunitinib in the United Kingdom, Germany, France and Italy. The average adverse event management costs varied across these countries but showed an overall trend of consistently lower costs for bevacizumab plus IFN versus sunitinib. Management costs varied between the countries, but country-specific cost calculations/tariff lists provide a probable explanation. In addition, direct costs from a prospective study may be needed to confirm the cost savings observed in this study. The linear decision analytical model used in this study used health-care costs according to standard clinical practice from a variety of sources and relied on adverse event data from individual clinical trials that may not be fully comparable or reflective of adverse events in daily clinical practice. In addition, the linear decision analytical model did not permit a statistical analysis of the cost differences between sunitinib and bevacizumab plus IFN nor did it permit an analysis of the effect of adverse events on treatment efficacy; additional studies may be needed to confirm these data. The study also highlights that there is no standardisation of treatment methods or costs across different countries, meaning that the potential effect of adverse event management costs should be assessed on an individual country basis. The poorly defined pathophysiology and manage- ment strategies of many sunitinib-associated adverse events may not have been captured by this analysis, that is, the potential of having to try different management approaches to identify the most effective may represent increased 'hidden' costs. Moreover, the analysis used costs for the management of haematological adverse events and hand-foot syndrome based on historical chemotherapy-associated costs. This could have underestimated the costs of managing sunitinib-associated adverse events. However, the utilisation of chemotherapy-associated costs will remain the standard approach until specific data for targeted therapies are available. Finally, this study did not consider drug administration costs or initial drug acquisition costs because country-specific initiatives may result in significant cost differences, making standardisation across countries difficult.

In conclusion, this study demonstrated that the different tolerability profiles of bevacizumab plus IFN and of sunitinib result in markedly lower adverse event management costs for bevacizumab plus IFN. As these regimens have comparable efficacy in the first-line treatment of metastatic RCC, the predicted cost savings in relation to the management of bevacizumab plus IFN could provide benefits to physicians and payers and may be an important consideration when making therapeutic choices. These findings raise important points and potential resource benefits in the current cost-conscious oncology environment, in which there is a demand for novel agents that provide the greatest benefit.

\section{ACKNOWLEDGEMENTS}

We acknowledge Prof JM Graf von der Schulenburg, Dr TH Mittendorf and Prof W Greiner (Centre for Health Economics and Health System Research, University of Hanover, Germany); and Dr A Lafuma (French College of Health Economics) for their support and provision of cost data. In addition, we acknowledge medical writing support of Gardiner-Caldwell Communications, Macclesfield, UK. The study and medical writing support were funded by F. Hoffmann-La Roche Ltd.

\section{REFERENCES}

Banque Claude Bernard, Group Cegedim, Boulogne Billancourt, France (2007). Available at: http://www.respi.fr

Base de données PMSI (2006) Agence Technique de l'Information sur l'Hospitalisation, Lyon, October 2006. Available at: http://www.atih. sante.fr/

Bukowski RM, Kabbinavar FF, Figlin RA, Flaherty K, Srinivas S, Vaishampayan U, Drabkin HA, Dutcher J, Ryba S, Xia Q, Scappaticci FA, McDermott D (2007) Randomized phase II study of erlotinib combined with bevacizumab compared with bevacizumab alone in metastatic renal cell cancer. J Clin Oncol 25: 4536-4541

Capri S, Morabito A, Carillio G, Grossi F, Longo R, Cerea G, Rossetti F (2007) Valutazione economica di erlotinib, docetaxel e pemetrexed nel trattamento di seconda linea del carcinoma polmonare non a piccole cellule. Pharmacoeconomics - Italian Research Articles 9: 113-124

Classification Commune des Actes Médicaux, CCAM V1 (2007). Available at: http://www.ameli.fr

Conferenza delle Regioni e Province Autonome. Tariffa Unica Convenzionale per le prestazioni di assistenza ospedaliera. Regole e tariffe valide per l'anno 2006. Roma, 15 December 2005

Coppin C, Le L, Porzsolt F, Wilt T (2008) Targeted therapy for advanced renal cell carcinoma. Cochrane Database Syst Rev 2: CD006017

Einheitlicher Bewertungsmaßstab für ärztliche Leistungen, Kassenärztliche Bundesvereinigung Berlin (2008) http://www.kbv.de/ebm2009/ EBMGesamt.htm

Elliott R (1996) An analysis of drug costs for the management of chemotherapy-related side effects in advanced colorectal cancer. J Oncol Pharm Practice 2: 186-190

Escudier B, Pluzanska A, Koralewski P, Ravaud A, Bracarda S, Szczylik C, Chevreau C, Filipek M, Melichar B, Bajetta E, Gorbunova V, Bay JO,
Bodrogi I, Jagiello-Gruszfeld A, Moore N, AVOREN Trial investigators (2007) Bevacizumab plus interferon alfa-2a for treatment of metastatic renal cell carcinoma: a randomised, double-blind phase III trial. Lancet 370: $2103-2111$

Escudier B, Bellmunt J, Negrier S, Melichar B, Bracarda S, Ravaud A, Golding S, Jethwa S, on behalf of the AVOREN investigators (2009) Final results of the phase III, randomised, double-blind AVOREN trial of firstline bevacizumab (BEV) + interferon- $\alpha 2 \mathrm{a}$ (IFN) in metastatic renal cell carcinoma (mRCC). J Clin Oncol 27(Suppl): 239s (Abstract 5020)

Etude Nationale de Coûts (2006) coûts de référence du secteur public, Agence Technique de l'Information sur l'Hospitalière, Lyon. Available at: http://www.atih.sante.fr/

Ferlay J, Autier P, Boniol M, Heanue M, Colombet M, Boyle P (2007) Estimates of the cancer incidence and mortality in Europe in 2006. Ann Oncol 18: $581-592$

G-DRG system (2008) Diagnosis Related Groups in Germany 2008. www.g-drg.de Houk HE, Bello CL, Michaelson MD, Bukowski RM, Redman BG, Hudes GR, Wilding G, Motzer RJ (2007) Exposure-response of sunitinib in metastatic renal cell carcinoma (mRCC): a population pharmacokinetic/ pharmacodynamic (PKPD) approach. J Clin Oncol 25(Suppl.): 241 s. (Abstract 5027)

Hurwitz H, Fehrenbacher L, Novotny W, Cartwright T, Hainsworth J, Heim W, Berlin J, Baron A, Griffing S, Holmgren E, Ferrara N, Fyfe G, Rogers B, Ross R, Kabbinavar F (2004) Bevacizumab plus irinotecan, fluorouracil, and leucovorin for metastatic colorectal cancer. $N$ Engl $J$ Med 350: $2335-2342$

Hutson TE, Figlin RA, Kuhn JG, Motzer RJ (2008) Targeted therapies for metastatic renal cell carcinoma: an overview of toxicity and dosing strategies. Oncologist 13: 1084-1096 
Jansen RB, Capri S, Nuijten MJC, Burrell A, Marini MG, Hardens M (1997) Economic evaluation of meloxicam $(7.5 \mathrm{mg})$ versus sustained release diclofenac $(100 \mathrm{mg})$ treatment for osteoarthritis: a cross-national assessment for France, Italy and the UK. Br J Med Econ 11: 9-22

Liou SY, Stephens JM, Carpiuc KT, Feng W, Botteman MF, Hay JW (2007) Economic burden of haematological adverse effects in cancer patients: a systematic review. Clin Drug Invest 27: 381-396

Manegold C, von Pawel J, Zatloukal P, Ramlau R, Gorbounova V, Hirsh V, Leighl N, Mezger J, Archer V, Reck M, the BO17704 study group (2007) Randomised, double-blind multicentre phase III study of bevacizumab in combination with cisplatin and gemcitabine in chemotherapy-naïve patients with advanced or recurrent non-squamous non-small cell lung cancer (NSCLC): BO17704. J Clin Oncol 25(Suppl.): 388s. (Abstract LBA7514)

Melichar B, Koralewski P, Ravaud A, Pluzanska A, Bracarda S, Szczylik C, Chevreau C, Filipek M, Delva R, Sevin E, Négrier S, McKendrick J, Santoro A, Pisa P, Escudier B (2008) First-line bevacizumab combined with reduced dose interferon- $\mid\{$ alphal\}2a is active in patients with metastatic renal cell carcinoma. Ann Oncol 19: 1470-1476

Mendel DB, Laird AD, Xin X, Louie SG, Christensen JG, Li G, Schreck RE, Abrams TJ, Ngai TJ, Lee LB, Murray LJ, Carver J, Chan E, Moss KG, Haznedar JO, Sukbuntherng J, Blake RA, Sun L, Tang C, Miller T, Shirazian S, McMahon G, Cherrington JM (2003) In vivo antitumour activity of Su11248, a novel tyrosine kinase inhibitor targeting vascular endothelial growth and platelet-derived growth factor receptors: determination of a pharmacokinetic/pharmacodynamic relationship. Clin Cancer Res 9: 327-337

Mickisch G, Escudier B, Gore M, Walzer S, Nuijten M (2009) Costs of managing side effects using first-line bevacizumab + lower-dose interferon- $\alpha 2 \mathrm{a}$ in patients with metastatic renal cell carcinoma in Germany, France and UK. Presented at: 2009 Genitourinary Cancers Symposium; 26-28 February 2009; Orlando, Fl. Abstract 312. Available at: http://www.asco.org

Mickisch G, Escudier BJ, Gore ME, Walzer S, Sabaté E, Nuijten M (2008) Costs of managing side effects in the treatment of first line metastatic renal cell carcinoma (mRCC) in Germany, France, and UK: Bevacizumab (BEV) + interferon alpha-2a (IFN) compared with sunitinib. J Clin Oncol 26(Suppl.): 277s. (Abstract 5110)

Miles D, Chan A, Romieu G, Dirix LY, Cortes J, Pivot X, Tomczak P, Taran T, Harbeck N, Steger GG (2008) Randomized, double-blind, placebocontrolled, phase III study of bevacizumab with docetaxel or docetaxel with placebo as first-line therapy for patients with locally recurrent or metastatic breast cancer (mBC): AVADO. J Clin Oncol 26(Suppl.): 1008s. (Abstract LBA1011)

Miller K, Wang M, Gralow J, Dickler M, Cobleigh M, Perez EA, Shenkier T, Cella D, Davidson NE (2007) Paclitaxel plus bevacizumab versus paclitaxel alone for metastatic breast cancer. $N$ Engl J Med 357: $2666-2676$
Mills EJ, Rachlis B, O'Regan C, Thabane L, Perri D (2009) Metastatic renal cell cancer treatments: an indirect comparison meta-analysis. $B M C$ Cancer 9: 34

Motzer RJ, Hutson TE, Tomczak P, Michaelson MD, Bukowski RM, Rixe O, Oudard S, Negrier S, Szczylik C, Kim ST, Chen I, Bycott PW, Baum CM, Figlin RA (2007) Sunitinib versus interferon alfa in metastatic renal-cell carcinoma. $N$ Engl J Med 356: 115-124

Negrier S, Figlin RA, Hutson TE, Tomczak P, Michaelson MD, Bukowski RM, Huang X, Kim ST, Chen I, Motzer RJ (2008) Overall survival with sunitinib versus interferon-alfa as first-line treatment of metastatic renal cell carcinoma. Ann Oncol 19(Suppl. 8): viii90. (Abstract 588PD)

Nuijten MJ, Berto P, Kosa J, Nadipelli V, Cimminiello C, Spreafico A (2002) Cost-effectiveness of enoxaparin as thromboprophylaxis in acutelly ill medical patients from the Italian NHS perspective. Recenti Prog Med 93: $80-91$

Pharmacie centrale des Hôpitaux de Paris (APHP). France, January 2007

Procopio G, Verzoni E, Bajetta E, Giuliani G, Peccerillo C, Walzer S, Nuijten M (2008) Costs of managing side effects in the treatment of first line metastatic renal cell carcinoma in Italy: Bevacizumab + Interferon alpha 2a compared with Sunitinib (ESMO poster P601). Ann Oncol 19(Suppl. 8): viii187 - viii207

Rini BI, Halabi S, Rosenberg JE, Stadler WM, Vaena DA, Ou SS, Archer L, Atkins JN, Picus J, Czaykowski P, Dutcher J, Small EJ (2008) Bevacizumab plus interferon alfa compared with interferon alfa monotherapy in patients with metastatic renal cell carcinoma: CALGB 90206. J Clin Oncol 26: $5422-5428$

Saltz LB, Clarke S, Diaz-Rubio E, Scheithauer W, Figer A, Wong R, Koski S, Lichinitser M, Yang TS, Rivera F, Couture F, Sirzén F, Cassidy J (2008) Bevacizumab in combination with oxaliplatin-based chemotherapy as first-line therapy in metastatic colorectal cancer: a randomized phase III study. J Clin Oncol 26: 2013-2019

Sandler A, Gray R, Perry MC, Brahmer J, Schiller JH, Dowlati A, Lilenbaum R, Johnson DH (2006) Paclitaxel-carboplatin alone or with bevacizumab for non-small-cell lung cancer. N Engl J Med 355: 2542 - 2550

Sutent (sunitinib). Summary of Product Characteristics. Available at: http:// emc.medicines.org.uk/emc/assets $/ \mathrm{c} / \mathrm{html} /$ displaydoc.asp?documentid = 18531

Thompson Coon JS, Liu Z, Hoyle M, Rogers G, Green C, Moxham T, Welch K, Stein K; Sunitinib and bevacizumab for first-line treatment of metastatic renal cell carcinoma: a systematic review and indirect comparison of clinical effectiveness. $\mathrm{Br} J$ Cancer, advance online publication, 30 June 2009

Table Nationale de codage de Biologie - Version 26 December (2007) Site de l'assurance maladie. Available at: http://www.ameli.fr

Yang JC, Haworth L, Sherry RM, Hwu P, Schwartzentruber DJ, Topalian SL, Steinberg SM, Chen HX, Rosenberg SA (2003) A randomized trial of bevacizumab, an anti-vascular endothelial growth factor antibody, for metastatic renal cancer. $N$ Engl J Med 349: 427-434 